\title{
CONSUMER PERCEPTION ON E-MARKETING STRATEGIES OF WECHAT EDUCATIONAL OFFICIAL ACCOUNTS
}

\author{
Yingran Guo and Zhiqiang Luan \\ International College Beijing, China Agricultural University, Beijing, 100083, P.R. China
}

\begin{abstract}
This paper discusses the current marketing strategy and the user perception of educational WeChat official accounts. The power of WeChat public accounts are rising in the social media world in China, and its function of public accounts has made simultaneous link sharing more convenient and viral. The existence of public account boosts many industries, including the current circumstance of education in a virtual learning environment and more interactive function. The researcher conveyed a survey toward undergraduate and graduate students to investigate the acceptance of existing marketing strategies in the educational field to find current shortcomings and potential improvements. The marketing strategies that the three mainstream educational accounts are using might not be accepted by major customers, while a precise distribution and better combination of information would benefit the accounts in the growing and competitive education market. This paper aims to find the real consumer perception of current widely-used marketing strategies. Language style, information type, marketing strategy, and accurate distribution are vital tools in boosting the marketing influence of educational accounts.
\end{abstract}

\section{KEYWORDS}

WeChat, e-Marketing, Consumer Satisfaction, Virtual Learning Environment, New Media Technology

\section{INTRODUCTION}

As the usage of mobile phones are becoming a substantial portion of people's social and personal lives, social media shapes our society dynamically. Providing worldwide users simultaneous messages indicates a chance for market strategy revolution, which requires a more customer-centered promoting method. In the decentralized social media age, the control of information sources has shifted from mere mainstream media to a mixture of mainstream sources, non-traditional key opinion leaders, and average social media user. WeChat, the dominant social media platform in China, has developed to 11.2 billion monthly active users by March 2019 (Tencent Holdings Ltd, 2019). This large consumer group covering various backgrounds expect to acquire dynamic information on the WeChat platform, including education resources. Low entrance cost, exponential growth, intense competition, and non-traditional methodology has brought the market into a pre-mature stage.

Therefore, WeChat educational public accounts must be aware of the upcoming breakthrough and meet consumer requirements. Based on the business model, we can divide these accounts into online-to-online and online-to-offline depending on the purpose of WeChat accounts. For the educational content and fields, there are official campus accounts, language education accounts, career opportunity accounts, higher education accounts, and personal promotion accounts. Each of these fields emerged several million-level leading brands. They provide a modern and efficient virtual learning environment on the WeChat platform to distribute diverse materials based on the official accounts function. As for the e-marketing strategy, there are many immature aspects that has yet to be promoted for higher consumer attention. 


\section{LITERATURE REVIEW}

This research aims to analyze the satisfaction of educational WeChat public account users and provide practical suggestions for brand promotion and e-marketing management. To gain the general idea of the WeChat public account and the virtual education environment, the author needs some reliable data from Tencent Company's 2019 quarter report and other relevant researches.

The customers' perception of WeChat information depends mainly on the choice-synthesize-understanding process. Cognition and environment both significantly influenced the acceptance of information on the WeChat platform (Chen, 2017). The current WeChat public account promotion method mainly relies on key opinion leaders and their reputation to obtain more extensive attention in the market (Wang, 2017). In the public educational accounts, the AISAS model (Attention-Interest-Search-Action-Share) is gradually being used in marketing strategies which require accounts to maintain a high frequency of updating, increasing the portion of original messages and improve the information quality (Feng, 2017). The current WeChat public account market is highly competitive and filled with possibilities with a large group of users of various ages, occupations, and geographical distribution.

Previous researches have examined multiple aspects of the interactive behaviours on the WeChat platform and its influences. Continuous use on a frequent basis defines the user stickiness, according to Lu et al. (2010). Visit duration and user retention both contribute to the user stickiness. Guo et al. (2017) proved that both extrinsic motivators (economic benefits such as coupons, discounts) and intrinsic motivators (general interests, curiosity satisfaction, self- expression and social identification) increased the tendency of fan engagement behaviour and stickiness on WeChat platform. Researchers also examined the interaction functions of participation motivation (intrinsic motivator X perceived entertainment), and perception of information quality (extrinsic motivator $\mathrm{X}$ perceived usefulness) are significant. Customers highly motivated by both intrinsic motivators and extrinsic motivations present stronger tendency on fan engagement behaviour.

Gan (2017) identified three major gratification influences on the liking behaviour of WeChat users. Hedonic gratification (enjoyment and passing time), social gratification (social support) and utilitarian gratification (information seeking and self-presentation) exert a positive impact on users' liking behaviour. Gender imposes a critical moderating variable for social media users since females value more on self-presentation (Haferkamp, Emiler, Papadakis, \& Kruck, 2012) and social expectations, such as interpersonal communication and maintaining relationships (Joiner et al., 2012; Kimbrough et al., 2013; Zhou et al., 2014). Gan believed on WeChat platform, entertaining and enjoyable contents stimulates male's liking behaviour while social support and useful information satisfy more of female needs.

Previous scholars examined the overall user behaviour on the WeChat platform and its stimuli factors without much focus on specific industries. Eductaion as one of the most desirable industry caters the needs of many WeChat users and creates the gap of researches on specific applications. This paper specifically analyzed the current consumer perception in the educational field to illuminate strategatic instructions for accompanies aiming at WeChat markets to follow.

\section{RESEARCH METHOD}

\subsection{Quantitative Research and Data Analysis}

Undergraduate and graduate students are the target audience to participate in the virtual learning process and their responsiveness directly indicates the e-marketing validity. Students' concerns provide practical insights for further development. The author designed a comprehensive questionnaire as the foundation of data analysis. Cluster analysis is used to gather features that are preferred by different customer groups for comparing and contrasting, from which we can sort customers by their preferences and distribute information by individual perceptions. By comparing different clusters, the consumer group of different sharing preferences testified the responsiveness for further suggestions on the e-marketing strategy. 


\subsection{Online Questionnaire}

To obtain a better understanding, the author designed a comprehensive questionnaire and surveyed several different universities across China, including China Agricultural University, Jincheng Normal University, and other colleges covering different levels and areas. The questionnaire also included graduate students from various major backgrounds to eliminate the possible bias reflected from one region, major or degree. We received 514 qualified responses in the data collection process.

\section{QUANTITATIVE RESEARCH}

\subsection{Reliability and Validity}

To make sure that the questionnaire design and data collection meets the requirement of credibility and reliability, we used Cronbach's Alpha as the standard for reliability. A score higher or equal to 0.6 on the Cronbach's Alpha test proves the credibility of the data set while a higher index implies higher reliability. As for the questionnaire conducted in the study, the Cronbach's Alpha score is 0.994, which confirmed the data set to be highly reliable for the latter explanation. Validity is another indicator of the credibility of the study. The Kaiser-Meyer-Olkin measures the sampling stands for the validity of the questionnaire. The KMO in this study is 0.993 , which shows that the correlated factors are significantly explaining the principal components in the questionnaire.

\subsection{Survey on Consumer Preference on Educational WeChat Public Account Marketing Strategy}

Based on the analysis of the multiple-choice questions, the preferred features of the educational WeChat public account are shown to have a various distribution among different groups.

Table 1. Accounts type preference

\begin{tabular}{llll}
\hline \multirow{2}{*}{ Item } & \multicolumn{3}{c}{ Popularizing rate } \\
& $\mathrm{N}$ & $\%$ & \\
\hline A、Official school & 356 & $29.5 \%$ & $68.9 \%$ \\
B、 Language study & 217 & $18.0 \%$ & $42.0 \%$ \\
C、 Occupation/internship & 167 & $13.8 \%$ & $32.3 \%$ \\
D、 Graduate study/Study abroad 145 & $12.0 \%$ & $28.0 \%$ \\
E、 Personal interest & 298 & $24.7 \%$ & $57.6 \%$ \\
F、Others & 24 & $2.0 \%$ & $4.6 \%$ \\
Total & 1207 & $100 \%$ & $233.5 \%$ \\
\hline
\end{tabular}

Table 1 shows the preference for educational account types and the official school accounts is shown to have the highest popularizing rate with a frequency of 356 and a universalization rate of $68.9 \%$. Personal interest accounts are the second most popular with a $24.7 \%$ popularizing rate. This field provides more of a non-traditional independent personal skill promotion beyond professional development. Major traditional accounts featuring language study, professional improvement, and higher education have been found to be less popular. 
Table 2. Information type preference

\begin{tabular}{cccc}
\hline Item & \multicolumn{3}{c}{ Popularizing rate universalization rate } \\
\hline A 、 Latest policy \& news & N & $\%$ & \\
B、 College culture & 278 & $23.9 \%$ & $53.8 \%$ \\
C、Activities (internship info \& academic conferences) & 237 & $20.4 \%$ & $45.8 \%$ \\
D、Study resources & 306 & $26.3 \%$ & $59.2 \%$ \\
E、 Discussion & 71 & $6.1 \%$ & $13.7 \%$ \\
F、Others & 15 & $1.3 \%$ & $2.9 \%$ \\
Total & 1163 & $100 \%$ & $225.0 \%$ \\
\hline Goodness of Fit: $\mathrm{X}^{2}=373.841 \mathrm{p}=0.000$ \\
\hline
\end{tabular}

Table. 2 shows the preferred information type among public account users. Study resources and the latest policy and news both have a universalization rate above $50 \%$ compared to the $13.7 \%$ universalization rate of the discussion part. The result suggests low interaction between users and WeChat accounts and emphasized on its one-way communication.

Table 3. Language type preference

\begin{tabular}{llll}
\hline \multirow{2}{*}{ Item } & \multicolumn{3}{c}{ Popularizing rate } \\
& $\mathrm{N}$ & $\%$ & \\
& Aniversalization rate $(\mathrm{N}=517)$ \\
B、 serious \& scientific 214 & $23.4 \%$ & $41.4 \%$ \\
B、 lively \& new & 283 & $30.9 \%$ & $54.7 \%$ \\
C、 amusing & 161 & $17.6 \%$ & $31.1 \%$ \\
D、 creative & 250 & $27.3 \%$ & $48.4 \%$ \\
E、 others & 8 & $0.9 \%$ & $1.5 \%$ \\
Total & 916 & $100 \%$ & $177.2 \%$ \\
\hline Goodness of Fit: $\mathrm{X}^{2}=254.142 \mathrm{p}=0.000$ \\
\hline
\end{tabular}

Table 3 suggested that readers appreciate lively and creative language the most but serious and scientific language also attracts $41.4 \%$ supporters in the universalization rate. The p-value from the goodness of fit tests supports the validity of the analysis. A p-value smaller than 0.05 reports a distinguishable difference among multiple options for further discussion. For all of the three tables, $\mathrm{p}$ values were all 0.000 .

\section{DATA ANALYSIS}

\subsection{Cluster Analysis}

Cluster analysis is used to divide respondents into subgroups with similar preferences to analyze different consumer behaviors. The researcher used K-means as the algorithm for cluster analysis to observe users' perceptions of different marketing strategies (Table.4). The K-means divided all respondents into three clusters depending on similar responses from the seven questions (Table.5). By clustering the target users, we're able to divide the audience into three subgroups of different sharing preferences in the e-marketing platform. The three subgroups reflect typical consumer groups in the real e-commerce situation. This allows us to understand the consumer composition better and testify the efficiency of these e-marketing strategies by analyzing the three clusters. 
Table 4. Cluster Analysis basic information-K-means

\begin{tabular}{lll}
\hline Clusters & $\mathrm{N}$ & $\%$ \\
\hline cluster_1 & 192 & $46.9 \%$ \\
cluster_2 & 173 & $42.3 \%$ \\
cluster_3 & 44 & $10.8 \%$ \\
Total & 409 & $100 \%$ \\
\hline
\end{tabular}

\subsection{Chi-Square Analysis}

The Chi-square test analyzes the different preferences for the clusters. The three clusters indicate a consistent attitude toward sharing strategy and tolerance level according to the survey data. $\mathrm{X}^{2}$ is the chi-square test statistic and p-value is an index showing the confidence of rejecting the null hypothesis. A high $\mathrm{X}^{2}$ score and lower p-value indicates a higher possibility of clusters correlating with the options.

Table 5. Crosstab (Chi-square) analysis of marketing strategy perception

\begin{tabular}{|c|c|c|c|c|c|c|c|}
\hline \multirow{2}{*}{ Question } & \multirow{2}{*}{ Option } & \multicolumn{3}{|c|}{ Cluster_Kmeans } & \multirow[t]{2}{*}{ Total } & \multirow[t]{2}{*}{$\mathrm{X}^{2}$} & \multirow{2}{*}{$\begin{array}{c}\text { p- } \\
\text { value }\end{array}$} \\
\hline & & Cluster_1 & Cluster_2 & Cluster_3 & & & \\
\hline \multirow{5}{*}{$\begin{array}{l}\text { Q1. Are you willing to } \\
\text { share a link in your } \\
\text { WeChat moments for } \\
\text { educational resources? }\end{array}$} & Strongly agree & $31(16.15)$ & $23(13.29)$ & $8(18.18)$ & $62(15.16)$ & \multirow{5}{*}{139.98} & \multirow{5}{*}{$0.000 * *$} \\
\hline & Agree & $131(68.23)$ & $26(15.03)$ & $27(61.36)$ & $184(44.99)$ & & \\
\hline & Disagree & $27(14.06)$ & $94(54.34)$ & $8(18.18)$ & $129(31.54)$ & & \\
\hline & Strongly disagree & $3(1.56)$ & $30(17.34)$ & $1(2.27)$ & $34(8.31)$ & & \\
\hline & Total & 192 & 173 & 44 & 409 & & \\
\hline \multirow{5}{*}{$\begin{array}{l}\text { Q2. What is the longest } \\
\text { time requirement can yc } \\
\text { accept to keep the link i } \\
\text { your WeChat moments } \\
\text { the educational public } \\
\text { account asks? }\end{array}$} & No more than 1 day & $52(27.08)$ & $140(80.92)$ & $23(52.27)$ & $215(52.57)$ & \multirow{5}{*}{145.335} & \multirow{5}{*}{$0.000 * *$} \\
\hline & 2-4 days & 102(53.13) & $15(8.67)$ & $4(9.09)$ & $121(29.58)$ & & \\
\hline & 4-7 days & $14(7.29)$ & $7(4.05)$ & $12(27.27)$ & $33(8.07)$ & & \\
\hline & More than 7 days & $24(12.50)$ & $11(6.36)$ & $5(11.36)$ & $40(9.78)$ & & \\
\hline & Total & 192 & 173 & 44 & 409 & & \\
\hline \multirow{5}{*}{$\begin{array}{l}\text { Q3. Are you willing to } \\
\text { collect "likes" in } \\
\text { WeChat moments for } \\
\text { educational resources? }\end{array}$} & Strongly agree & $26(13.54)$ & $19(10.98)$ & $8(18.18)$ & $53(12.96$ & \multirow{5}{*}{134.687} & \multirow{5}{*}{$0.000 * *$} \\
\hline & Agree & $110(57.29)$ & $11(6.36)$ & 26(59.09) & $147(35.94)$ & & \\
\hline & Disagree & $45(23.44)$ & 102(58.96) & $7(15.91)$ & 154(37.65) & & \\
\hline & Strongly disagree & $11(5.73)$ & $41(23.70)$ & $3(6.82)$ & $55(13.45)$ & & \\
\hline & Total & 192 & 173 & 44 & 409 & & \\
\hline \multirow{5}{*}{$\begin{array}{l}\text { Q4. What is the most } \\
\text { number of "likes" } \\
\text { requirement you can } \\
\text { accept as the } \\
\text { educational public } \\
\text { account asks? }\end{array}$} & No more than 10 & $13(6.77)$ & $82(47.40)$ & $2(4.55)$ & $97(23.72)$ & \multirow{5}{*}{160.894} & \multirow{5}{*}{$0.000 * *$} \\
\hline & $10-20$ & 118(61.46) & $45(26.01)$ & $5(11.36)$ & 168(41.08) & & \\
\hline & $20-40$ & 40(20.83) & $32(18.50)$ & $34(77.27)$ & 106(25.92) & & \\
\hline & More than 40 & 21(10.94) & 14(8.09) & $3(6.82)$ & $38(9.29)$ & & \\
\hline & Total & 192 & 173 & 44 & 409 & & \\
\hline \multirow{5}{*}{$\begin{array}{l}\text { Q5. Are you willing to } \\
\text { forward links to } \\
\text { WeChat group chat for } \\
\text { educational resources? }\end{array}$} & Strongly agree & $30(15.63)$ & $23(13.29)$ & $9(20.45)$ & $62(15.16)$ & \multirow{5}{*}{155.696} & \multirow{5}{*}{$0.000 * *$} \\
\hline & Agree & $114(59.38)$ & $8(4.62)$ & $26(59.09)$ & $148(36.19)$ & & \\
\hline & Disagree & $40(20.83)$ & $99(57.23)$ & $7(15.91)$ & $146(35.70)$ & & \\
\hline & Strongly disagree & $8(4.17)$ & $43(24.86)$ & $2(4.55)$ & $53(12.96)$ & & \\
\hline & Total & 192 & 173 & 44 & 409 & & \\
\hline \multirow{5}{*}{$\begin{array}{l}\text { Q6. How many WeChat } \\
\text { groups at most would } \\
\text { you like to forward } \\
\text { links to for educational } \\
\text { resources? }\end{array}$} & 1 & $48(25.00)$ & $121(69.94)$ & $12(27.27)$ & $181(44.25)$ & \multirow{5}{*}{131.623} & \multirow{5}{*}{$0.000 * *$} \\
\hline & 2 & $106(55.21)$ & $30(17.34)$ & $8(18.18)$ & $144(35.21)$ & & \\
\hline & & $22(11.46)$ & $17(9.83)$ & $22(50.00)$ & $61(14.91)$ & & \\
\hline & More than 3 & $16(8.33)$ & $5(2.89)$ & $2(4.55)$ & $23(5.62)$ & & \\
\hline & Total & 192 & 173 & 44 & 409 & & \\
\hline
\end{tabular}




\begin{tabular}{|c|c|c|c|c|c|c|c|}
\hline \multirow[t]{2}{*}{ Question } & \multirow[t]{2}{*}{ Option } & \multicolumn{3}{|c|}{ Cluster_Kmeans } & \multirow[t]{2}{*}{ Total } & \multirow[t]{2}{*}{$\mathrm{X}^{2}$} & \multirow[t]{2}{*}{$\begin{array}{c}\text { p- } \\
\text { value }\end{array}$} \\
\hline & & Cluster_1 & Cluster_2 & Cluster_3 & & & \\
\hline \multirow{5}{*}{$\begin{array}{l}\text { Q7. Which are the } \\
\text { resources you want to } \\
\text { get from these } \\
\text { marketing strategies? }\end{array}$} & Discounts & $17(8.85)$ & $33(19.08)$ & $23(52.27)$ & $73(17.85)$ & \multirow{4}{*}{60.953} & \multirow{5}{*}{$0.000 * *$} \\
\hline & Study materials & 152(79.17) & $105(60.69)$ & 11(25.00) & $268(65.53)$ & & \\
\hline & Online courses & $20(10.42)$ & 28(16.18) & $9(20.45)$ & 57(13.94) & & \\
\hline & Others & $3(1.56)$ & $7(4.05)$ & $1(2.27)$ & $11(2.69)$ & & \\
\hline & Total & 192 & 173 & 44 & 409 & & \\
\hline \multicolumn{5}{|c|}{$* p<0.05 * * p<0.01$} & & & \\
\hline
\end{tabular}

P-values listed in Table 5 shows that the three clusters in all of the seven questions have $\mathrm{p}=0.000 * *$, which means there is a significant correlation between answers and clusters. The table also presents the frequency and percentages.

From the cluster analysis and chi-square analysis, the separate clusters show a consistent level of acceptance on the three market strategies. Cluster 3 shows the most active respondents toward the WeChat e-marketing strategy by taking up $10 \%$ of the results. Cluster 2 shows the least active respondents toward the WeChat marketing strategy, which is $42.3 \%$ of the results. Cluster 1 shows medium active respondents to the WeChat e-marketing strategy, with $46.9 \%$ of the total respondents. Within the three strategies listed, sharing links in WeChat moment is most accepted by users, followed by sharing links to the WeChat group. Collecting likes are relatively less acceptable for educational WeChat public account users. As for the preferred educational resource as a promotion strategy, most active respondents (Cluster 3) preferred discounts while the inactive group (Cluster 1) showed a higher interest in study materials.

\section{CONCLUSION}

In the educational WeChat public account development, choice of account type, content type, and language type should better meet the aesthetic and needs of current students by being more personal, informative, updated and adding other preferred characteristics. Young users tend to require individualized settings according to various interests on top of the necessary information. Many functional education accounts fail to meet this requirement. The existing market strategy of encouraging users to forward and share the accounts could increase information exposure exponentially while users tend to show a negative feeling toward these strategies. Account managers should take into account the distribution of different groups by using a mixture of study materials and discounts as attention grabbing tools. Generally, customers are still conservative on the current mainstream e-marketing strategies for educational WeChat public accounts, which urge educational public account designers to develop more acceptable promotional methods. Other innovations such as inter-platform e-marketing and more interactive e-marketing strategy would also boost consumer satisfaction in the virtual education environment based on the WeChat official account function.

\section{REFERENCES}

Chen, J., 2017. The information perception of college students based on WeChat platform, Heilongjiang University, Heilongjiang,

Chen. X., 2015. The WeChat public account brand image promotion analysis based on AISAS model, Art and Science, pp 279-280

Chen, X., 2017. The marketing strategy of WeChat public account on the study of soft articles, Shenyang Normal University, Shenyang,

Feng, Y., 2017. A study on the content marketing strategy of the official WeChat public platform in a university, Capital University of Economics and Business, Beijing,

Gan, C., 2017. Understanding WeChat users' liking behavior: An empirical study in China. Computers in Human Behavior, pp 30-39. https://doi.org/10.1016/j.chb.2016.11.002

Guo, L., Zhang, M., Kang, K., \& Hu, M., 2017. Transforming followers into fans: A study of Chinese users of the we Chat Official Account. Online Information Review, pp 1029-1045. https://doi.org/10.1108/OIR-01-2016-0013 
Haferkamp, N., Eimler, S. C., Papadakis, A.-M., \& Kruck, J. V., 2012. Men Are from Mars, Women Are from Venus? Examining Gender Differences in Self-Presentation on Social Networking Sites, Cyberpsychology, Behavior, and Social Networking, pp 91-98. doi: 10.1089/cyber.2011.0151

Joiner, R., Gavin, J., Brosnan, M., Cromby, J., Gregory, H., Guiller, J., Moon, A., 2012. Gender, Internet Experience, Internet Identification, and Internet Anxiety: A Ten-Year Followup. Cyberpsychology, Behavior, and Social Networking, 15(7), pp 370-372. doi: 10.1089/cyber.2012.0033

Lu, H.P. and Lee, M.R.,2010, "Demographic differences and the antecedents of blog stickiness", Online Information Review, Vol. 34 No. 1, pp. 21-38.

Tencent Holdings Limited, 2019. Tencent 2019 First Quarter Results, Tencent Holdings Ltd, available at: https://www.tencent.com/en-us/articles/15000771557911821.pdf, [Accessed: May 22nd, 2019] 